OPEN ACCESS

Edited by:

Eugenia Bezirtzoglou,

Democritus University of Thrace,

Greece

Reviewed by:

Pierangeli Vital,

University of the Philippines Diliman,

Philippines

Zeyou Chen

Nankai University, China

*Correspondence:

Aklilu Feleke Haile

ataklilu@yahoo.com

Specialty section:

This article was submitted to

Food Microbiology,

a section of the journal

Frontiers in Microbiology

Received: 13 April 2021

Accepted: 17 June 2021

Published: 16 July 2021

Citation:

Haile AF, Alonso S, Berhe N,

Bekele Atoma T, Boyaka PN and

Grace D (2021) Escherichia coli

0157:H7 in Retail Lettuce (Lactuca

sativa) in Addis Ababa City:

Magnitude of Contamination

and Antimicrobial Susceptibility

Pattern. Front. Microbiol. 12:694506.

doi: 10.3389/fmicb.2021.694506

\section{Escherichia coli 0157:H7 in Retail Lettuce (Lactuca sativa) in Addis Ababa City: Magnitude of Contamination and Antimicrobial Susceptibility Pattern}

\author{
Aklilu Feleke Haile ${ }^{1,2 *}$, Silvia Alonso ${ }^{3}$, Nega Berhe $^{1}$, Tizeta Bekele Atoma ${ }^{4}$, \\ Prosper N. Boyaka5,6,7 and Delia Grace ${ }^{8,9}$ \\ ${ }^{1}$ Aklilu Lemma Institute of Pathobiology, Addis Ababa University, Addis Ababa, Ethiopia, ${ }^{2}$ Department of Veterinary \\ Biosciences, The Ohio State University, Columbus, OH, United States, ${ }^{3}$ International Livestock Research Institute (ILRI), \\ Addis Ababa, Ethiopia, ${ }^{4}$ Ethiopian Public Health Institute, Addis Ababa, Ethiopia, ${ }^{5}$ Department of Veterinary Biosciences, \\ College of Veterinary Medicine, The Ohio State University, Columbus, $\mathrm{OH}$, United States, ${ }^{6}$ Department of Microbial Immunity \\ and Infection, The Ohio State University, Columbus, $\mathrm{OH}$, United States, ${ }^{7}$ Infection Diseases Institute, The Ohio State \\ University, Columbus, $\mathrm{OH}$, United States, ${ }^{8}$ International Livestock Research Institute (ILRI), Nairobi, Kenya, ${ }^{9}$ Natural \\ Resources Institute, Chatham, United Kingdom
}

Escherichia coli $\mathrm{O} 157: \mathrm{H} 7$ is an important foodborne pathogen but largely under investigated in Africa. The objectives of this study were to estimate the prevalence and pattern of antimicrobial resistance of E. coli O157:H7 in lettuce in Addis Ababa, Ethiopia. A total of 390 retail lettuce samples were collected across the 10 subcities of Addis Ababa. E. coli O157:H7 was isolated and identified following ISO-16654:2001 standard. The isolates were further tested for antimicrobial susceptibility to 13 antimicrobials using the Kirby-Bauer disk diffusion method. Out of the 390 lettuce samples examined, two $(0.51 \%)$ carried E. coli $\mathrm{O} 157: \mathrm{H} 7$. The antimicrobial susceptibility pattern of strains showed resistance to ampicillin (100\%) and tetracycline $(50.0 \%)$. One of the two isolates was multidrug resistant to two antimicrobials tested. The results of this study demonstrate the presence of drug-resistant E. coli 0157:H7 in lettuce in markets in Addis Ababa. Despite the low prevalence, its presence in a product that is eaten raw highlights potential public health risk in the area associated with this pathogen.

Keywords: Addis Ababa, antimicrobial, Escherichia coli 0157:H7, lettuce, prevalence

\section{INTRODUCTION}

Foodborne illnesses are a crucial cause of morbidity and mortality, and a big impediment to socioeconomic development worldwide (WHO, 2015). The incidence of foodborne disease appears to be increasing globally (Jaffee et al., 2018). For industrialized countries, it has been estimated that up to one-third of the population suffers at least one foodborne episode each year. Considering the problems of sanitation in the developing world, the prevalence of foodborne disease can be assumed to be even higher (Käferstein, 2003; Grace, 2015). 
Escherichia coli is a bacterium that colonizes the intestinal track of animals and humans. Most strains of E. coli are harmless and are considered part of the normal gut flora. However, specific strains such as E. coli O157:H7 have the ability to produce toxins that can cause severe illness (Wang et al., 2014). E. coli O157:H7 infection in humans has different clinical manifestations ranging from asymptomatic (carrier state) to more complicated forms of the disease that includes hemorrhagic colitis (HC), hemolytic uremic syndrome (HUS), thrombotic thrombocytopenic purpura (TTP), and even death. While the disease can affect any age group, its most severe forms are mostly seen in children less than 5 years, elders greater than 65 years, and immunocompromised individuals (Boyce et al., 1995; Mead and Griffin, 1998; Moses et al., 2006).

Consumption of vegetables contaminated with $E$. coli O157:H7 has been associated with many outbreaks around the world. Lettuce has been associated to many outbreaks of E. coli O157:H7. In the United States, outbreaks of E. coli O157:H7 infections have been caused by lettuce and alfalfa sprouts (Laven, 2006). Lettuce has been associated to many outbreaks of E. coli O157:H7. Contamination of lettuce with foodborne pathogenic microorganisms can occur at several points along the value chain, from the field to the market (Barak et al., 2002; Lelieveld et al., 2003). The use of manure from cattle as fertilizer or the close proximity of the vegetable fields or water supplies to cattle farms have been associated with contamination of vegetables (Elder et al., 2000; Ibenyassine et al., 2007).

Antibiotic resistance is an increasingly concerning health issue across the globe (Käferstein, 2003). Cattle and other ruminants can be asymptomatic carriers of E. coli O157:H7 (Meng and Doyle, 1998) and, through exposure to antimicrobial drugs in the livestock production system, may serve as a source of antimicrobial-resistant bacteria.

The three major types of vegetable retailers in Addis Ababa are roadside retailers (individuals selling in improvised spots or basic stalls along the streets), open market retailers (sellers with basic stalls within an open market), street shops (within a fixed premise along the street), and supermarkets. Addis Ababa has two large open markets that serve as central points for the distribution of vegetables coming from rural and peri-urban areas to be sold and consumed in the city. These main vegetable markets are called "Piazza" and "Mercato," and approximately 50\% of their supplies originate from smallholder producers or farmers' cooperatives. Many other types of vegetable retailers across the city source their vegetables at these markets (Wiersinga and de Jager, 2009; Setegn, 2015).

The increasing popularity of fast food, in particular burgers, which use raw lettuce as an ingredient, as well as the use of lettuce in salad as a common side dish in Addis Ababa's restaurants raises questions around the safety of this product and its potential health risks. No information is available on the magnitude of contamination and antimicrobial susceptibility patterns of E. coli O157:H7 in Addis Ababa, and in the rest of Ethiopia.

The present study was designed to estimate the prevalence of E. coli O157:H7 serotype in lettuce from selected lettuce retail outlets in Addis Ababa, Ethiopia, as well as to determine the antimicrobial susceptibility pattern of E. coli O157:H7 serotypes.

\section{MATERIALS AND METHODS}

\section{Study Area}

The study was carried out in Addis Ababa, the capital city of Ethiopia. The city covers $540 \mathrm{~km}^{2}$ and is divided into 10 subcities. The city lies at an elevation of $2,355 \mathrm{~m}$ above sea level and is located at $9^{\circ} 1^{\prime} 48^{\prime \prime} \mathrm{N} 38^{\circ} 44^{\prime} 24^{\prime \prime} \mathrm{E}$. The city has a minimum, maximum, and average temperature of 14,21 , and $17.5^{\circ} \mathrm{C}$, respectively. Addis Ababa has bimodal rainfall with an annual average of 1,800 $\mathrm{mm}$ with the highest of rain falls during the long rainy season from June to September. The short rainy season is from February to April. The capital city has an estimated human population of 3.15 million (CSA, 2010).

\section{Study Design and Sample Size Determination}

A cross-sectional study was conducted from October 2018 to December 2019 to determine the prevalence and antimicrobial susceptibility of E. coli O157:H7 serotype in retail raw lettuce samples obtained from selected vegetable retail outlets, in Addis Ababa.

The sample size required was calculated according to the formula in Thrusfield (2018):

$$
\mathrm{n}=\mathrm{Z}^{2} \mathrm{P}_{\exp }\left(1-\mathrm{P}_{\exp }\right) / \mathrm{d}^{2}
$$

where $\mathrm{Z}=\mathrm{z}$ statistic for level of confidence; $\mathrm{n}$ = required sample size; $\mathrm{P}_{\text {exp }}$, the expected prevalence and; $\mathrm{d}$ the desired absolute precision. We used an expected E. coli O157:H7 prevalence of $50,5 \%$ precision, and level of confidence of $95 \%$. The calculated sample size required was 384 .

\section{Sampling Methods}

Addis Ababa has 10 subcities. Across the 10 subcities, 390 vegetable retail outlets were conveniently included in the study. A lettuce sample was purchased from each of the outlets in the same fashion as they are sold to the buyers.

Each lettuce sample was placed in a sterile individual plastic bag. The sample was identified by its exclusive sample identification number, which was written on the plastic bag, alongside the subcity and date of sampling. Finally, the sample was transported to the Microbiology Laboratory of the Aklilu Lemma Institute of Pathobiology, Addis Ababa University, at cold temperature in a cool box. Upon arrival to the laboratory, the samples were stored in a refrigerator at $\pm 4^{\circ} \mathrm{C}$. The samples were processed within 6-12 h from arrival. Detection of E. coli O157:H7 was done using an ISO-16654:2001 standard (ISO, 2001).

\section{Sample Preparation and Enrichment}

The inner and outer leaves of the lettuce were cut by a sterile scalpel to form a 25-g sample and put in a sterile Stomacher bag. Then, $225 \mathrm{ml}$ of modified Tryptone Soya Broth (TSB) supplemented with Novobiocin $(\mathrm{mTSB}+\mathrm{N})(1: 9)$ was added to the lettuce and homogenized using a homogenizer (Stomacher 400, Seward Medical, England) at high speed for 
$2 \mathrm{~min}$. The enrichment sample was then incubated aerobically at $41.5^{\circ} \mathrm{C}$ for $24 \mathrm{~h}$.

\section{Isolation}

Detection of E. coli O157:H7 was done using ISO-16654:2001 standard (Manyi-Loh et al., 2018). All enriched broths were plated onto cefixime tellurite sorbitol MacConkey agar (CTSMAC) that was sorbitol MacConkey agar (Oxoid, England), supplemented with $0.05 \mathrm{mg} / \mathrm{L}$ cefixime and potassium $2.5 \mathrm{mg} / \mathrm{L}$ tellurite (Oxoid, England) (CT-SMAC) (Oxoid, England) and incubated at $37^{\circ} \mathrm{C}$ for $24 \mathrm{~h}$. Following the end of the incubation period, the CT-SMAC agar plates were examined for the presence of non-sorbitol fermenter colorless colonies, and subsequently they were subcultured on Rainbow agar O157 (Hayward, United States). The plates were then incubated for $20-4 \mathrm{~h}$, at $37^{\circ} \mathrm{C}$ and observed for the presence of typical black or gray coloration on Rainbow agar O157, which shows pure colonies (Biolog, 2008).

\section{Biochemical Confirmation}

Five typical colonies from each Rainbow agar O157 plate were subcultured on nutrient agar (Oxoid, England) for biochemical confirmation by indole formation. The agar plates were incubated at $37^{\circ} \mathrm{C}$ for $18-24 \mathrm{~h}$. One colony from the pure culture on the nutrient agar was inoculated into a tube of tryptone/tryptophan medium (Oxoid, England) and incubated at $37^{\circ} \mathrm{C}$ for $24 \mathrm{~h}$. Then, $1 \mathrm{ml}$ of Kovack's (Oxoid, England) was added, and the tube was allowed to stand at room temperature for $10 \mathrm{~min}$. The formation of red color indicates a positive reaction (Manyi-Loh et al., 2018).

\section{Serological Identification of 0157 and $\mathrm{H7}$ Antigens}

Latex agglutination was performed for confirmation of E. coli O157:H7 using an RIM E. coli O157:H7 latex test kit (Oxoid, England) (Manyi-Loh et al., 2018). The latex kit has four compartments: latex test reagent, latex control reagent, the positive controls, and negative controls. The particle in each reagent was coated with a different antibody against E. coli serotype $\mathrm{O} 157$ or E. coli serotype H7, and therefore the control was coated with normal rabbit globulin. The positive and negative controls are suspensions of formalin-killed E. coli O157:H7 cells and non-specific E. coli cells, respectively.

Indole-positive colonies were examined for their serological reaction with antiserum to $E$. coli O157:H7 using an RIM E. coli O157:H7 latex test (Oxoid, England). Indole-positive colonies were subcultured from the nutrient agar to the sorbitol MacConkey agar (Oxoid, England). For every isolate to be tested, one drop of test latex was dispensed into a well of the test slide. In like manner, one drop of $E$. coli control latex was dispensed into a separate well of the test slide. Using a plastic stick, a portion of the non-sorbitol fermenting colony (NSFC) was removed from the sorbitol MacConkey agar-SMAC (Oxoid, England) plate, emulsified in E. coli O157 test latex on the slide, and spread over the reaction area. Using a fresh plastic stick, the process was repeated with the remaining NSFC and emulsified in E. coli control, latex on the slide. The slide was rotated using circular motions for up to $1 \mathrm{~min}$ or until agglutination appeared. For E. coli $\mathrm{O} 157$ positives that agglutination occurs with the E. coli O157 test latex and the control latex is negative, the isolate was streaked from sorbitol MacConkey agar (Oxoid, England) to a blood agar (Oxoid, England) plate and incubated at $37^{\circ} \mathrm{C}$ for 18-24 h. After 18-24 h of incubation, the sweep of growth from the blood agar plate was emulsified in a drop of E. coli H7 test latex. Colonies giving an agglutination reaction were confirmed as E. coil O157:H7 positive.

\section{Molecular Conformation of E. coli 0157}

Isolates were confirmed by polymerase chain reaction (PCR) for the O157 lipopolysaccharide O-antigen synthesis $r f b E \mathrm{O} 157$ gene. The reactions were performed using oligonucleotide primer set specific for $r f b E O 157$ gene (Thermo Fisher Scientific, United States). Primers for the amplification of the rfbEO157 genes are rfbEO157-F 5'-AAG ATT GCG CTG AAG CCT TTG-3' and rfbEO157 R-5'-CAT TGG CAT CGT GTG GAC AG-3' rfbEO157 producing 497 bp of $r f b E O 157$ gene (Desmarchelier et al., 1998).

The PCR was performed using Illustra ${ }^{\mathrm{TM}}$ PuReTaq $^{\mathrm{TM}}$ Ready-To-Go ${ }^{\text {TM }}$ PCR Beads (GE Healthcare Bio-Sciences, United States) in $25 \mu \mathrm{l}$ reaction using SimpliAmp Thermal Cycler (Applied Biosystems, Singapore). The PCR reaction mixtures were subjected to the following conditions in SimpliAmp Thermal Cycler: an initial denaturation of one cycle at $95^{\circ} \mathrm{C}$ for $5 \mathrm{~min}$, followed by 35 cycles, each consisting of $94^{\circ} \mathrm{C}$ for $30 \mathrm{~s}$, $66^{\circ} \mathrm{C}$ for $30 \mathrm{~s}, 72^{\circ} \mathrm{C}$ for $30 \mathrm{~s}$, and a final extension at $72^{\circ} \mathrm{C}$ for $10 \mathrm{~min}$ (Desmarchelier et al., 1998).

Amplification products were resolved by electrophoresis in $2 \%$ agarose gels, stained with ethidium bromide. The gel was run for at $100 \mathrm{~V}$ for $40 \mathrm{~min}$ and then visualized with UV light using AlphaImager instrument and FluorChem HD2 software. Product sizes were determined by comparison with a 100-bp gene ruler DNA ladder (Thermo Fisher Scientific, United States).

\section{Antimicrobial Susceptibility Testing}

The antimicrobial susceptibility was performed following the standard agar disk diffusion method consistent with CLSI (2014) using commercial antimicrobial disks (Table 1).

Each isolated bacterial colony from pure fresh culture was transferred into a tube of $5 \mathrm{ml} \mathrm{TSB}$ (Oxid, England) and incubated at $37^{\circ} \mathrm{C}$ for $6 \mathrm{~h}$. The turbidity of the culture broth was adjusted using sterile saline solution or added more colonies to get turbidity, usually comparable with that of $0.5 \mathrm{McFarland}$ standards (approximately $3 \times 10^{8} \mathrm{CFU}$ per ml). Mueller-Hinton agar (Oxiod, England) plates were prepared consistent with the manufacturer. A sterile cotton swab was immersed into the suspension and rotated against the side of the tube to get rid of the sulplus fluid and then swabbed in three directions uniformly on the surface of Mueller-Hinton agar plates. After the plates dried, antibiotic disks were sited on the inoculated plates using sterile forceps. The antibiotic disks were gently pressed onto the agar to ensure firm contact with the agar surface, and incubated at $37^{\circ} \mathrm{C}$ for $24 \mathrm{~h}$. Following this the diameter of the inhibition zone formed around each disk was measured using a black surface, reflected light, and transparent ruler by 
TABLE 1 | Antibiotic disks used to test E. coli O157:H7 and their respective concentrations.

\begin{tabular}{|c|c|c|c|c|c|c|}
\hline \multirow[t]{2}{*}{ No. } & \multirow[t]{2}{*}{ Antibiotic disks } & \multirow[t]{2}{*}{ Disk code } & \multirow[t]{2}{*}{ Concentration } & \multicolumn{3}{|c|}{ Diameter of zone of inhibition in millimeter $(\mathbf{m m})$} \\
\hline & & & & Resistant $\leq$ & Intermediate & Susceptible $\geq$ \\
\hline 1 & Ampicillin & AM & $10 \mu \mathrm{g}$ & 13 & $14-16$ & 17 \\
\hline 2 & Amoxycillin-clavulanic acid & AMC & $20 / 10 \mu g$ & 13 & $14-17$ & 18 \\
\hline 3 & Amikacin & AK & $30 \mu \mathrm{g}$ & 14 & $15-16$ & 17 \\
\hline 4 & Ciprofloxacin & CIP & $5 \mu \mathrm{g}$ & 15 & $16-20$ & 21 \\
\hline 5 & Ceftriaxone & $\mathrm{CRO}$ & $30 \mu \mathrm{g}$ & 19 & $20-22$ & 23 \\
\hline 6 & Cefoxitin & FOX & $30 \mu \mathrm{g}$ & 14 & $15-17$ & 18 \\
\hline 7 & Nitrofurantoin & $\mathrm{F} / \mathrm{M}$ & $50 \mu \mathrm{g}$ & 14 & $15-16$ & 17 \\
\hline 8 & Kanamycin & $\mathrm{K}$ & $30 \mu \mathrm{g}$ & 13 & $14-17$ & 18 \\
\hline 9 & Nalidixic acid & NA & $30 \mu \mathrm{g}$ & 13 & $14-18$ & 19 \\
\hline 10 & Sulfamethoxazole-trimethoprim & SXT & $25 \mu \mathrm{g}$ & 10 & $11-15$ & 16 \\
\hline 11 & Tetracycline & TE & $30 \mu \mathrm{g}$ & 11 & $12-14$ & 15 \\
\hline 12 & Streptomycin & S & $10 \mu \mathrm{g}$ & 11 & $12-14$ & 15 \\
\hline 13 & Gentamicin & GM & $10 \mu \mathrm{g}$ & 12 & $13-14$ & 15 \\
\hline
\end{tabular}

lying it over the plates. The isolates were classified as sensitive, intermediate, and resistant according to the breakpoints of the clinical interpretative criteria recommended by CLSI guidelines (CLSI, 2014). E. coli (ATCC 25922) was used as a positive control.

\section{Ethical Consideration}

The study protocol was ethically approved by the Institutional Review Board of Aklilu Lemma Institute of Pathobiology, Addis Ababa University (Minutes Ref NO: ALIPB IRB/006/2011/2018).

\section{Data Management and Analysis}

The data were entered and coded in MS Excel and then analyzed using IBM SPSS version 25.0 (SPSS, 2017). The prevalence was determined by dividing the number of positive samples by the total number of samples examined. Descriptive statistics such as frequency and percentages were used to describe the proportion of resistant, intermediate, or susceptible strains. The difference in prevalence by subcity was determined using chi-square $\left(\chi^{2}\right)$ test. A $p$-value $<0.05$ was considered indicative of a statistically significant difference.

\section{RESULTS}

\section{Prevalence}

A total of 390 retail lettuces samples were collected from vegetable retailer outlets in Addis Ababa, 39 in each of the 10 subcities. Out of 390 lettuce samples examined, two (0.51\%) (95\% $\mathrm{CI}=-0.2-1.23)$ were positive to $E$. coli $\mathrm{O} 157: \mathrm{H7}$.

The positive samples were from outlets in Bole and Yeka subcities. However, the prevalence of E. coli O157:H7 was not statistically significant $(\chi 2=8.041 ; d f=9, p=0.530(p>0.05)$ among the subcities of vegetable retail outlets (Table 2 ).

\section{Antimicrobial Susceptibility Pattern of E. coli 0157:H7}

Both isolates were resistant to ampicillin. One of the isolates, the one from Bole subcity, showed additional resistance to
TABLE 2 | Prevalence of $E$. coli O157:H7 by risk factor.

\begin{tabular}{|c|c|c|c|c|c|c|}
\hline \multicolumn{2}{|c|}{ Risk factor } & \multirow{2}{*}{$\begin{array}{c}\begin{array}{l}\text { Number } \\
\text { examined }\end{array} \\
39\end{array}$} & \multirow{2}{*}{$\begin{array}{c}\text { Positive } \\
\text { no (\%) }\end{array}$} & \multirow{2}{*}{$\frac{x^{2}}{8.041}$} & \multirow{2}{*}{$\begin{array}{c}\boldsymbol{d f} \\
9\end{array}$} & \multirow{2}{*}{$\frac{\boldsymbol{p} \text {-Value }}{0.530}$} \\
\hline Sub-city & Addis Ketema & & & & & \\
\hline & Akaki Kality & 39 & 0 & & & \\
\hline & Arada & 39 & 0 & & & \\
\hline & Bole & 39 & $1(6.25)$ & & & \\
\hline & Gullele & 39 & 0 & & & \\
\hline & Kirkos & 39 & 0 & & & \\
\hline & Kolfe Keraneo & 39 & 0 & & & \\
\hline & Lideta & 39 & 0 & & & \\
\hline & Nefassilk & 39 & 0 & & & \\
\hline & Yeka & 39 & $1(6.25)$ & & & \\
\hline
\end{tabular}

TABLE 3 | Antimicrobial susceptibility pattern of E. coli O157:H7 isolates $(n=2)$.

\begin{tabular}{lccc}
\hline Antimicrobial use & $\begin{array}{c}\text { Sensitive } \\
\text { no. (\%) }\end{array}$ & $\begin{array}{c}\text { Intermediate } \\
\text { no. (\%) }\end{array}$ & $\begin{array}{c}\text { Resistant } \\
\text { no. (\%) }\end{array}$ \\
\hline Ampicillin (AM) & $0(0)$ & $0(0)$ & $2(100)$ \\
Amoxicillin-clavulanate (AMC) & $2(100)$ & $0(0)$ & $0(0)$ \\
Amikacin (AK) & $1(50)$ & $1(50)$ & $0(0)$ \\
Ciprofloxacin (CIP) & $1(50)$ & $1(50)$ & $0(0)$ \\
Ceftriaxone (CRO) & $2(100)$ & $0(0)$ & $0(0)$ \\
Cefoxitin (FOX) & $2(100)$ & $0(0)$ & $0(0)$ \\
Nitrofurantoin (F/M) & $1(50)$ & $1(50)$ & $0(0)$ \\
Kanamycin (K) & $1(50)$ & $1(50)$ & $0(0)$ \\
Nalidixic acid (NA) & $2(100)$ & $0(0)$ & $0(0)$ \\
Sulfamethoxazole-trimethoprim (SXT) & $2(100)$ & $0(0)$ & $0(0)$ \\
Tetracycline (TE) & $1(50)$ & $0(0)$ & $1(50)$ \\
Streptomycin (S) & $1(50)$ & $1(50)$ & $0(0)$ \\
Gentamicin (GM) & $1(50)$ & $1(50)$ & $0(0)$ \\
\hline
\end{tabular}

tetracycline. Both isolates were susceptible to five antibiotics: amoxicillin-clavulanic acid, ceftriaxone, cefoxitin, nalidixic acid, and sulfamethoxazole-trimethoprim (Table 3). 


\section{DISCUSSION}

Our study is the first to report the presence of E. coli O157:H7 in lettuce in Ethiopia. The prevalence was low $0.51 \%$ (95\% $\mathrm{CI}=-0.2-1.23)$. Studies in other countries have reported similar low prevalence. Studies have reported zero prevalence 7 in Spain and Mexico (Canizalez-Roman et al., 2013; Castro-Ibáñez et al., 2015). Higher prevalence has been reported in Pakistan (2.0\%) (Shah et al., 2015) and in Iran (10.0\%) (Shakerian et al., 2016).

The prevalence of $E$. coli $\mathrm{O} 157: \mathrm{H} 7$ was not statistically significant $(p>0.05)$ among the subcities of vegetable retail outlets. This might be due to outlets across the city source their vegetables from the same main vegetable markets, Piazza, and Mercato (Wiersinga and de Jager, 2009). The small number of positives also means a much larger sample size would be needed to identify any differences.

Antimicrobial resistance is a one health issue, with connecting the health of people, animals, and the environment in a complex web of causation (Käferstein, 2003). The E. coli O157:H7 isolates in this study showed resistance to ampicillin $(100 \%)$ and tetracycline $(50.0 \%)$. There are no other similar studies in Ethiopia. However, resistance to the same antibiotics has been reported in studies in Iran [ampicillin (100\%) and tetracycline (87\%)] (Shakerian et al., 2016) and in Pakistan [ampicillin (87\%) and tetracycline (92\%)] (Shah et al., 2015). On the other hand, among the two E. coli O157:H7 isolates from lettuce, one isolate showed multidrug resistance to ampicillin and tetracycline. Comparable to the present study, multidrug resistance was recorded from Iran (Shah et al., 2015; Shakerian et al., 2016). However, no studies have been found in Ethiopia. The resistance pattern might be related the broad use of tetracycline among livestock (Gemeda et al., 2020) and ampicillin in management of various infections in Ethiopia (Eguale et al., 2015).

The present study had a limitation in laboratory facility. The use of immune-magnetic separation (IMS) with enrichment in broth culture is commonly used to enhance the isolation of E. coli $\mathrm{O} 157$ from samples with an expected low concentration

\section{REFERENCES}

Barak, J., Whitehand, L., and Charkowski, A. (2002). Differences in attachment of Salmonella enterica serovars and Escherichia coli O157: H7 to alfalfa sprouts. Appl. Environ. Microbiol. 68, 4758-4763. doi: 10.1128/aem.68.10.4758-4763. 2002

Biolog (2008). Data Collection Software Identification System User Guide.2008. Hayward CA: Biolog.

Boyce, T. G., Swerdlow, D. L., and Griffin, P. M. (1995). Escherichia coli O157: H7 and the hemolytic-uremic syndrome. New Engl. J. Med. 333, 364-368.

Canizalez-Roman, A., Gonzalez-Nuñez, E., Vidal, J. E., Flores-Villaseñor, H., and León-Sicairos, N. (2013). Prevalence and antibiotic resistance profiles of diarrheagenic Escherichia coli strains isolated from food items in northwestern Mexico. Int. J. Food Microbiol. 164, 36-45. doi: 10.1016/j.ijfoodmicro.2013.03.020

Castro-Ibáñez, I., Gil, M., Tudela, J., and Allende, A. (2015). Microbial safety considerations of flooding in primary production of leafy greens: a case study. Food Res. Int. 68, 62-69. doi: 10.1016/j.foodres.2014.05.065

Chapman, P., Wright, D., and Siddons, C. (1994). A comparison of immunomagnetic separation and direct culture for the isolation of bacteria (Chapman et al., 1994). In our study, we used enrichment without IMS for the isolation of $E$ coli O157:H7. More general proxies of fecal contamination such as coliforms and Enterobacteriaceae would have been useful indicators of the microbiological safety of the lettuce, but this was outside the reach of our study. Nevertheless, the present study is the first to report the existence of E. coli O157:H7 in lettuce samples in Ethiopia and its antimicrobial resistant patterns. This information calls for larger and duly powered studies to understand the sources, the points of contamination, and define appropriate risk mitigation strategies for the country.

\section{DATA AVAILABILITY STATEMENT}

The raw data supporting the conclusions of this article will be made available by the authors, without undue reservation.

\section{AUTHOR CONTRIBUTIONS}

AH conceived and designed the study, conducted the study, analyzed the data, and wrote the manuscript. SA conceived the study, provided guidance to its design, and reviewed the manuscript. NB designed the study, analyzed the data, and wrote the manuscript. TB conducted the study and analyzed the data. $\mathrm{PB}$ reviewed the manuscript and wrote the manuscript. DG conceived and designed study, analyzed the data, and reviewed the manuscript. All authors contributed to the article and approved the submitted version.

\section{ACKNOWLEDGMENTS}

This study was received financial support from the CGIAR Research Program on Agriculture for Nutrition and Health. In addition, the molecular conformation was supported by Global One Health Initiative (GOHi), The Ohio State University.

of verocytotoxin-producing Escherichia coli 0157 from bovine faeces. J. Med. Microbiol. 40, 424-427. doi: 10.1099/0022261540-6-424

CLSI (2014). Performance standards for antimicrobial susceptibility testing. Twenty Forth Information Supplement (M 100-524). Services. . MMWR 54. Wayne, PA: CLSI, 1277-1280.

CSA (2010). The 2007 Population and Housing Census. Seattle WA: CSA.

Desmarchelier, P. M., Bilge, S. S., Fegan, N., Mills, L., Vary, J. C., and Tarr, P. I. (1998). A PCR specific for Escherichia coli O157 based on the rfb locus encoding O157 lipopolysaccharide. J. Clin. Microbiol. 36, 1801-1804. doi: 10.1128/jcm. 36.6.1801-1804.1998

Eguale, T., Gebreyes, W. A., Asrat, D., Alemayehu, H., Gunn, J. S., and Engidawork, E. (2015). Non-typhoidal Salmonella serotypes, antimicrobial resistance and coinfection with parasites among patients with diarrhea and other gastrointestinal complaints in Addis Ababa, Ethiopia. BMC Infect. Dis. 15:497.

Elder, R. O., Keen, J. E., Siragusa, G. R., Barkocy-Gallagher, G. A., Koohmaraie, M., and Laegreid, W. W. (2000). Correlation of enterohemorrhagic Escherichia coli O157 prevalence in feces, hides, and carcasses of beef cattle during processing. Proc. Natl. Acad. Sci.U.S.A. 97, 2999-3003. doi: 10.1073/pnas.97.7.2999 
Gemeda, B. A., Amenu, K., Magnusson, U., Dohoo, I., Hallenberg, G. S., Alemayehu, G., et al. (2020). Antimicrobial use in extensive smallholder livestock farming systems in Ethiopia: knowledge, attitudes, and practices of livestock keepers. Front. Vet. Sci. 7:55.

Grace, D. (2015). Food safety in low and middle income countries. Int. J. Environ. Res. Public Health 12, 10490-10507. doi: 10.3390/ijerph120910490

Ibenyassine, K., Mhand, R. A., Karamoko, Y., Anajjar, B., Chouibani, M., and Ennaji, M. (2007). Bacterial pathogens recovered from vegetables irrigated by wastewater in Morocco. J. Environ. Health 69, 47-51.

ISO (2001). 16654. Microbiology of Food and Animal Feeding Stuffs - Horizontal Method for the Detection of Escherichia coli O157. Geneva: ISO, 1-13.

Jaffee, S., Henson, S., Unnevehr, L., Grace, D., and Cassou, E. (2018). The Safe Food Imperative: Accelerating Progress in Low-And Middle-Income Countries. Washington, DC: World Bank Publications.

Käferstein, F. (2003). Actions to reverse the upward curve of foodborne illness. Food Control 14, 101-109. doi: 10.1016/s0956-7135(02)00017-8

Laven, R. (2006). Diagnosis of calf diarrhoea: a different perspective? UK Vet Livestock 11, 36-38. doi: 10.1111/j.2044-3870.2006.tb00004.x

Lelieveld, H. L., Mostert, M., White, B., and Holah, J. (2003). Hygiene in Food Processing: Principles and Practice. Amsterdam: Elsevier.

Manyi-Loh, C., Mamphweli, S., Meyer, E., and Okoh, A. (2018). Antibiotic use in agriculture and its consequential resistance in environmental sources: potential public health implications. Molecules 23, 795. doi: 10.3390/molecules23040795

Mead, P. S., and Griffin, P. M. (1998). Escherichia coli O157: H7. Lancet 352, 1207-1212.

Meng, J., and Doyle, M. (1998). Emerging and evolving microbial foodborne pathogens. Bull. l'Institut. Pasteur 96, 151-163. doi: 10.1016/s0020-2452(98) 80010-9

Moses, A., Garbati, M., Egwu, A., and Ameh, E. (2006). Detection of E. coli 0157 and 026 serogroups in human immunodeficiency virus-infected patients with clinical manifestation of diarrhoea in Maiduguri. Nigeria. Res. J. Med. Med. Sci. $1,140-145$.

Setegn, D. (2015). Analysis of Vegetable Market Chain in Dugda woreda, East Shoa Zone, Oromia Region, Ethiopia, MA Thesis. in Regional and
Local Development Studies. Addis Ababa, Ethiopia. Ethiopia: Addis Ababa University.

Shah, M. S., Eppinger, M., Ahmed, S., Shah, A. A., Hameed, A., and Hasan, F. (2015). Multidrug-resistant diarrheagenic E. coli pathotypes are associated with ready-to-eat salad and vegetables in Pakistan. J. Korean Soc. Appl. Biol. Chem. 58, 267-273. doi: 10.1007/s13765-015-0019-9

Shakerian, A., Rahimi, E., and Emad, P. (2016). Vegetables and restaurant salads as a reservoir for Shiga toxigenic Escherichia coli: distribution of virulence factors, O-serogroups, and antibiotic resistance properties. J. Food Protect. 79, 1154-1160. doi: 10.4315/0362-028x.jfp-15-517

SPSS (2017). IBM SPSS Statistics for Windows. Armonk, NY: SPSS.

Thrusfield, M. (2018). Veterinary Epidemiology. Hoboken NJ: John Wiley \& Sons.

Wang, S., Zhang, S., Liu, Z., Liu, P., Shi, Z., Wei, J., et al. (2014). Molecular characterization of enterohemorrhagic E. coli $\mathrm{O} 157$ isolated from animal fecal and food samples in Eastern China. Sci. World J. 14, 2014.

WHO (2015). WHO ESTIMATES OF THE GLOBAL BURDEN OF FOODBORNE DISEASES. Available online at https://apps.who.int/iris/bitstream/handle/ 10665/200046/WHO_FOS_15.02_eng.pdf?sequence=1 (accessed February 21, 2021).

Wiersinga, R. C., and de Jager, A. (2009). Business Opportunities in the Ethiopian Fruit and Vegetable Sector. The Hague: LEI Wageningen UR.

Conflict of Interest: The authors declare that the research was conducted in the absence of any commercial or financial relationships that could be construed as a potential conflict of interest.

Copyright (c) 2021 Haile, Alonso, Berhe, Bekele Atoma, Boyaka and Grace. This is an open-access article distributed under the terms of the Creative Commons Attribution License (CC BY). The use, distribution or reproduction in other forums is permitted, provided the original author(s) and the copyright owner(s) are credited and that the original publication in this journal is cited, in accordance with accepted academic practice. No use, distribution or reproduction is permitted which does not comply with these terms. 